\title{
Por uma história cultural latino-americana dos meios de comunicação: um olhar sobre as práticas, processos e sistemas de comunicação nas últimas décadas do século XIX ${ }^{1}$
}

Marialva Carlos Barbosa*

Resumo: O trabalho tem como foco as perspectivas teóricas e metodológicas que devem ser adotadas para se pensar numa história cultural latino-americana dos meios de comunicação. Para tanto, analisa as dificuldades teóricas de se pensar os meios de comunicação na perspectiva da história cultural ultrapassando fronteiras e espaços culturais específicos. Num segundo momento, apresenta como possibilidade analítica a perspectiva de olhar um território espacial, como território midiático, pensando práticas, processos e sistemas de comunicação para tornar possível a análise a partir de uma perspectiva histórica e cultural dos processos de comunicação existentes em diversos territórios latinos-americanos. O ponto central do exercício reflexivo são as transformações da imprensa nas últimas décadas do século XIX.

Palavras-chave: Comunicação. História. Metodologia. América Latina.

\footnotetext{
* Professora Titular de Jornalismo da Escola de Comunicação da Universidade Federal do Rio de Janeiro (UFRJ). Vice-presidente da INTERCOM e pesquisadora do CNPq. Doutora em História pela Universidade Federal Fluminense (UFF) e pós-doutora em Comunicação pelo LAIOS/CNRS (França).
} 
Por uma história cultural latino americana dos meios de comunicação:...

\section{Introdução}

Antes de enfocar especificamente sobre as transformações da imprensa nas últimas décadas do século XIX, na perspectiva metodológica de se pensar a análise histórica dos meios de comunicação a partir das práticas comunicacionais, é necessário fazer algumas considerações sobre a forma teórica e metodológica das pesquisas em torno da questão histórica dos meios de comunicação.

Ainda que haja uma nítida predominância, nos estudos históricos dos meios de comunicação, de trabalhos que privilegiam os veículos (e seus discursos) ou personagens singulares que se transformam em espécie de esteio desse passado, na história que propomos interessa os processos e as práticas de comunicação que se desenvolvem invariavelmente num circuito também de comunicação. Desvelar este circuito significa particularizar os veículos, mas também incluir os atores que neles atuavam como jornalistas ou outros profissionais, as discursividades que produziram e com que sentidos. Significa perceber ainda quem eram os sujeitos a quem se destinava aquela experiência e como esses que, a posteriori, denominamos público estenderam os sinais emitidos pelos meios de comunicação. Ou seja, propomos que a história da comunicação seja sempre história dos processos e das práticas comunicacionais cujo procedimento metodológico desvende o circuito da comunicação (no caso dos jornais, o que eram e como eram os jornais, quem eram os jornalistas, que discurso eles produziram, que relações estabeleciam com outros grupos na sociedade, para quem escreviam e que tipo de apropriação o público fazia daquelas mensagens). Mas, é claro que desenvolver uma pesquisa que procura desvendar o circuito de comunicação existente no passado apresenta enormes dificuldades.

Seguindo a tendência dos estudos de humanidades, desde o último decênio do século XX, procuramos interpretar atos dos sujeitos históricos envolvidos em processos comunicacionais. Portanto, a história que revelamos diz respeito à ação humana, muito mais do que as tentativas de desvendar a forma ou o conteúdo dos meios de comunicação. 
Partimos da idéia de que é possível acessar o passado a partir de rastros comunicacionais produzidos, rastros que perduraram no tempo exatamente porque foram práticas de comunicação que se inscreveram em múltiplos suportes memoráveis. Em última instância, o que temos acesso para tentar adentrar no passado são atos de comunicação: traços de uma cultura material, resquícios de falas impressas, audíveis, manuscritas, imagens que teimam em perdurar em variados suportes.

No nosso entendimento, uma história dos meios deve colocar a questão da comunicação como centro da reflexão e não apenas tentar descrever o conteúdo das mensagens ou remontar como se caracterizava a mídia de outrora. A história da comunicação destaca processos comunicacionais, visualizados a partir das práticas comunicativas dos atores do passado e das suas apropriações e das interpretações que produziram de seus modos de comunicação (incluindo aí, seu contato com os meios de comunicação).

Quando o foco é deslocado para as práticas, interessa interpretar as ações desses atores num jogo de trocas com o mundo social. A história da comunicação transmuta-se na história das práticas comunicativas dos atores do passado e, mais do que isso, das suas apropriações e interpretações.

\section{Premissas para uma história da comunicação}

Algumas outras especificidades devem ser consideradas quando o foco é a realização de estudos que objetivam recuperar processos comunicacionais localizados no passado. A primeira, a que já nos referimos pontualmente logo no início desse texto, diz respeito ao fato de ser essa uma história dos sistemas de comunicação, na qual é preciso dar voz e rosto aos múltiplos atores envolvidos: produtores de textos, produtores gráficos, distribuidores, editores, leitores etc. Além disso, é preciso que se considerem as materialidades produzidas, ou seja, os suportes que deram vida aos processos de comunicação e que colocaram em circulação, num espaço social, formas impressas, visuais, sonoras etc. 
Por uma história cultural latino americana dos meios de comunicação:...

Não se trata de recuperar os conteúdos dos impressos ou das emissões, visualizando nos múltiplos discursos a essência de uma história que, dessa maneira, aborda apenas a dimensão textual da obra. Não se trata de produzir história a partir da ênfase nas ações de atores privilegiados, os fundadores ou dirigentes de jornais, revistas, emissoras de rádio e de televisão etc. Recuperar a trajetória de jornalistas singulares, dos proprietários dos veículos, ou seja, dos grandes personagens não constrói a história que propomos: quando muito oferece a sensação de dívida para aqueles que, por múltiplos trabalhos memoráveis localizados no futuro, importantes inclusive para a produção de mitificações em torno das profissões, são elevados à condição de figuras emblemáticas, transformando-se em verdadeiros ícones de uma fatia do passado que se quer preservar por razões de natureza política.

A segunda especificidade diz respeito ao objeto de análise: indo além dos veículos e de seus produtores, essa história deve revelar o processo comunicacional envolvido em múltiplas relações narrativas. Processos que colocam em cena complexos circuitos de comunicação e que podem, a partir dos rastros que chegam ao presente, serem mapeados. Teórica e metodologicamente, é preciso descortinar o que essas práticas sociais envolviam: produtores de textos, suportes, estratégias e o público que escreve, com sua leitura, parte fundamental dessas narrativas. Tem importância o conteúdo, o produtor da mensagem, a forma como o leitor/espectador entendeu nos limites da sua cultura os sinais emitidos ou impressos, ou seja, a apropriação diferenciada feita pelo ele, sujeito social e histórico.

Portanto, ao invés de tentar analisar os meios, é preciso, tal como já enfatizava Martín-Barbero (1987) no penúltimo decênio do século XX, ir em direção às mediações localizadas no passado. São os atores sociais que constroem a história da comunicação e não os veículos considerados na sua singularidade. $\mathrm{Na}$ direção do redemoinho das práticas (REVEL, 2009, p. 210) adotado por inúmeras disciplinas, a história da comunicação deve privilegiar a ação humana. Ao invés de se buscar instituições, funções, dispositivos, máquinas e gramáticas, há que se pensar na forma como os atores sociais constroem práticas comunicacionais numa longa história de criação de próteses para tornar mais eficiente o ato comunicacional. 
Há que se perceber, enfim, que a história comunicacional do homem foi construída pela adoção de diversas próteses comunicacionais que fizeram e ampliaram a possibilidade do ato comunicativo. À prótese fala seguiu-se outra tecnologia, a escrita, e, assim, sucessivamente, numa extensa construção de mediações possíveis para tornar mais eficiente o ato de comunicar. Portanto, a história da comunicação é a reconstrução, pelo ato interpretativo, dessas múltiplas mediações e de suas materializações em processos complexos.

A terceira especificidade diz respeito ao produto que é colocado em circulação pelos meios de comunicação. Considerando que as textualidades (ampliando, portanto, a noção de texto além do que é escritura e percebendo as visualidades e as sonoridades também como textualidades) são produtos históricos de uma época, aquilo que os meios de comunicação anunciam como discursividade está sempre entranhado de história. É preciso, assim, escavar os meandros dos textos, indo além das intenções de quem os produziu, atrás das vozes incontroladas de que fala Ginzburg (2007, p. 11). Todo documento (inclusive aqueles que consideramos e classificamos como ficcionais) produz um testemunho involuntário que se encontra nas suas profundezas narrativas ou nas suas fimbrias textuais.

Mas aqui temos um problema epistemológico. Ao produzir textualidades no presente para o futuro, os meios de comunicação, possuindo uma dimensão documental, transformam-se em espécies de fiadores das épocas, retirando do mundo aspectos que devem ser guardados para a história. A narrativa do cotidiano transmuta-se em documentos que serão, no futuro, novamente recuperados para caracterizar aquele momento e lugar. Portanto, na história dos meios de comunicação está inscrita também a documentação produzida para caracterizar momentos qualificados como históricos e acontecimentos dignos de serem assim considerados.

Os meios de comunicação, no presente (como a história em relação ao passado), têm como objetivo a fiabilidade, ou seja, ambos querem representar a realidade, o que de fato existe ou existiu. Ambos são modos narrativos que procuram a representância no sentido que Paul Ricoeur atribuiu à palavra (2007). Por representância entende-se a cristalização de expectativas da história e a sua 
Por uma história cultural latino americana dos meios de comunicação:...

intencionalidade. O que é objetivado pelo conhecimento histórico pressupõe um pacto que permite ao historiador descrever situações que existiram antes de sua própria existência. A representância implica sempre uma relação do texto com seu referente e, no caso do texto histórico, esse referente é o rastro.

Concordamos inteiramente com a proposição de que a história é fiadora de um passado que é revelado (e explicado) pela ação de renarrar. Assim, nas vezes que afirmamos a "característica ficcional" da história, não estávamos retirando da disciplina a sua característica de representância, mas apenas reafirmando que, buscando o verdadeiro, a história introduz o verossímil, já que permite que cada um siga uma história que possui começo, meio e fim e que, por isso, torna-se inteligível. História é reconstrução, interpretação onde estão incluídas necessariamente visões de mundo do presente. Visões de mundo como forma de imaginação, texto como arte-fato literário, onde se reconhece o papel ativo da linguagem na criação e na descrição da realidade histórica. Afinal, o passado nos chega sob forma de mensagens, textualidades que são transformadas em contexto pela ação do pesquisador. Para isso há que se reconstruir a diversidade a partir de vestígios múltiplos e esparsos, e identificar as estratégias utilizadas pelos produtores de texto.

Ao afirmar o caráter ficcional da narrativa histórica estamos, portanto, enfatizando a dimensão interpretativa do relato histórico. Os fatos não são dados objetivos ou descobertas, sendo elaborados sempre a partir do tipo de pergunta que o pesquisador - que também está imerso em lutas por representações - faz acerca dos fenômenos que se colocam diante dele. E, por último, e o mais importante, com essa perspectiva estamos remarcando a sua dimensão narrativa.

Como última reflexão, resta referirmo-nos à questão do valor do conhecimento passado. Não é todo o passado que valorizamos: desse passado tornado presente, elegemos um aspecto, demarcamos como fundamentais momentos axiais que instauram rupturas no terceiro tempo, o tempo da histórica, o tempo calendário (RICOEUR, 2007). Mas essa seleção memorável depende, também, do valor atribuído a cada época histórica (Heller, 1993). Em diferentes momentos da nossa história, em idades anteriores, sempre houve alguma coisa que um mortal não deveria saber. Esse conhecimento podia ser conside- 
rado, por exemplo, demoníaco ou uma forma de transgressão moral. Portanto, o conhecimento é um valor que possui as possibilidades das épocas históricas em que se vive. A história, como afirma Dilthey, é a autobiografia de pessoas e da humanidade. Da mesma forma que cotidianamente reescrevemos a história de nossas vidas, a humanidade reescreve novamente sua biografia (HELLER, 1993, p. 107).

Considerando ainda que a história referencie sempre o fracasso ou o sucesso de homens que vivem e trabalham juntos em sociedades, com pretensão ou ao verdadeiro ou ao verossímil, ela é fragmento ou segmento do mundo da comunicação. São os atos comunicacionais dos homens do passado o que se pretende recuperar como verdade absoluta ou como algo capaz de ser acreditado como verídico. É nesse sentido que a história é ato comunicacional. É a partir de restos e vestígios que chegam do passado ao presente que podemos recontar as histórias que envolvem prioritariamente as ações comunicacionais do passado.

Mas como interpretar o passado à luz das visões de mundo dos homens do passado? Como adentrar no espírito de uma época percebendo valores que não são mais os nossos?

Encontramo-nos mais uma vez diante do problema da cientificidade: é a adoção de normas, preceitos, teorias, metodologias que, na essência, indicam a possibilidade de visualizar o passado de forma verdadeira. Assim, valores de outrora, interpretados à luz da compreensão presente do pesquisador, tornam-se, pela questão da fiabilidade de a história falar do passado, o verdadeiro passado. Procura-se encontrar nos rastros deixados, marcas que revelam, pela interpretação produzida e permitida, um mundo que, até então, fora desconhecido. São os princípios normativos produzidos no presente que permitem o acesso a um passado considerado real, já que o que é formulado pela historiografia deve ser a verdade (ou o conhecimento verdadeiro).

Da mesma forma, é uma questão de valor perceber nos vestígios determinadas mensagens desse passado. Se houver, numa determinada época, a consciência histórica disponível para enxergá-las e, posteriormente, interpretá-las, pode-se ter uma história a ser contada dentro das normas da cientificidade da disciplina. 
Por uma história cultural latino americana dos meios de comunicação:...

Pensar historicamente enriquece a reflexão sobre o universo comunicacional. Evidentemente a referência não é à história como disciplina, mas a um olhar historiográfico, a uma maneira filosófica de perceber o mundo como universo histórico. Isto é, descortinar as relações temporais, a forma como nos apropriamos e nos inserimos no tempo, ou seja, qual é a lógica temporal do mundo que construímos.

Pensar historicamente é colocar em primazia a visão processual do mundo e perceber as práticas e processos comunicacionais como próprios de um momento e lugar. As generalizações em história, só são possíveis depois dos particularismos. A história, portanto, é a forma como nos sentimos na duração, como nos visualizamos como ser, ao longo de uma trajetória, que classificamos como existência num espaço (que, por vezes, denominamos mundo). A história é a nossa relação silenciosa ou ruidosa com os estasses do tempo: o presente, o passado e o futuro. A história é o fato de estarmos no mundo. Do presente, do nosso agora sempre transitório, olhamos o passado e projetamos o futuro. Mas o passado só existe como representação mental a partir do olhar individual daquele que o descortina nos tempos idos. Portanto, o passado não é fixo: é materializado pelas recordações e sempre transformado pela interpretação que fazemos. Assim, como o passado não é fixo, também o presente não é apenas um instante pontual. O presente indica o que vivemos, mas também as rememorações que o passado proporciona. Essas rememorações existem sempre no presente, construindo-o pelo entrelaçamento do mesmo (as ações vividas no presente) e do outro (as rememorações que fazem o passado presente).

Proponho, portanto, pensarmos a história da comunicação latino-americana desde esta perspectiva, isto é, considerando a comunicação como um processo e recuperando os sistemas de comunicação existentes no tempo como modos de comunicação realizados por múltiplos atores envolvidos nesses processos. Talvez devêssemos pensar em territórios midiáticos nos quais, com diferentes modelos e especificidades, desenvolveram-se transformações nos modos de comunicação. 


\section{A criação das fábricas de notícias}

Que diferenças substanciais e que aproximações podemos fazer, por exemplo, em relação às drásticas transformações que ocorreram no mundo latino-americano no que diz respeito aos modos de comunicação com o início do que alguns chamam imprensa de informação?

Se há diferenças temporais em relação ao início da operação dos jornais como "fábricas de notícias" nos diversos territórios geopolíticos, com diferenças de décadas a partir dos três últimos terços do século XIX, processos semelhantes se espalharam pelas principais cidades capitais. Há, portanto, a formação de um território midiático comum, nos quais processos comunicacionais semelhantes passam a configurar novos modos de comunicação.

Na criação das "fábricas de notícias" (isto é, jornais diários que conquistam público), publicidade e poder inserem-se nesse processo, cuja senha é dada pela modernização compulsória de diversas cidades, que, em consonância com a adoção de práticas tecnológicas, se construíam como ícones de um progresso elevado à idéia de civilização.

Nos grandes centros, em diversos países latino-americanos, há, portanto, um território midiático comum caracterizado pela criação de novos modos de comunicação, a partir da proliferação de periódicos cuja estratégia última é a conquista de um público mais vasto, num longo processo, que desaguará na formação de uma sociedade de massas. As tecnologias comunicacionais telégrafos, telefones, máquinas linotipos, máquinas impressoras, máquinas fotográficas e, posteriormente, máquinas de escrever etc. - permitem, naquele primeiro momento, isto é, no final do século XIX e início do século XX, transformações estonteantes na forma como se fazia jornais.

De modo geral, a cena urbana nessas cidades capitais é invadida por tecnologias que transformam o imaginário e a maneira como se via o mundo. Cinematógrafo, fonógrafo, gramofone, daguereótipos, linotipos, impressoras Marinonis, máquinas de um mundo que transformam as percepções visuais, auditivas e táteis. A entrada em cena desses aparelhos tecnológicos altera a percepção do público que passa a ter nos seus modos de comunicação a intermediação de meios que produzem outras mediações. 
Por uma história cultural latino americana dos meios de comunicação:...

Nesse mundo que se maravilhava com os inventos que invadiam as cenas das grandes metrópoles, também os jornais e as revistas, cada vez mais ricamente ilustradas, incluem em seus modos de produção apêndices tecnológicos que permitiram com que a palavra de ordem do momento - rapidez - fosse deslocada para a forma como os meios de comunicação deveriam ser concebidos. Com isso, os periódicos podiam ser produzidos por máquinas linotipos capazes de substituir o trabalho de até 12 compositoras manuais; máquinas de imprimir podiam "vomitar" até 20 mil exemplares por hora; máquinas de fotografar que podiam reproduzir em imagens o que antes podia ser apenas descrito. Os periódicos transformam gradativamente seus modos de produção e o discurso com que se auto-referenciam. Passam a ser ícones de modernidade, em cidades símbolos desse novo tempo.

Essas tecnologias capazes de fornecer uma dimensão à concepção temporal e espacial são decisivas na conformação do novo mundo simbólico que emerge nessas últimas décadas do século XIX e primeiros anos do século XX em territórios governados por uma nova lógica midiática. $\mathrm{O}$ mundo se torna próximo e visível. As descrições e a possibilidade de ver, em imagens, lugares longínquos e figuras exóticas mudam a percepção do outro, agora visível, e antes apenas imaginado. A possibilidade de saber o que se passa no mundo em poucas horas constrói gradativamente outra espacialização. O mundo se torna mais compacto. A temporalidade ganha nova dimensão.

Os jornais, sobretudo aqueles que querem consolidar sua força junto ao público e, consequentemente, sua ingerência política, deviam implantar esses novos artefatos tecnológicos, permitindo maior tiragem, maior qualidade e maior rapidez na impressão. Era preciso também diminuir as distâncias entre o acontecimento e o público.

Constrói-se também, paulatinamente, a imagem do jornalismo como conformador da realidade e da atualidade. E as tecnologias, mais uma vez, são fundamentais para a construção do jornalismo como lugar da informação neutra e atual. Se o telégrafo torna os acontecimentos visíveis, há que informar, cada vez mais, os fatos que ocorrem próximos ao público. A opinião é, assim, gradativamente separada de uma idéia de informação isenta e, nesse processo, os novos artefatos tecnológicos desempenham papel fundamental. 


\section{Marialva Carlos Barbosa}

Para conquistar mais leitores, um tipo de notícia passa a ter primazia: as de natureza policial. Com o mesmo objetivo assiste-se à difusão do folhetim. Os jornais publicam também charges diárias, colunas, os escândalos sensacionais, dentre uma gama variável de assuntos, com a preocupação maior de atingir um universo significativo, vasto e heterogêneo de leitores.

As explicações para a inclusão das chamadas notas sensacionais nas páginas dos diários e para a absorção dessas narrativas por ampla parcela da população podem ser de inúmeras ordens, mas devem ser explicadas sempre no contexto histórico de sua produção. Em primeiro lugar é preciso considerar a questão da narrativa. Do ponto de vista do texto, essas notícias possuem marcas singulares: alicerçadas nos fatos anteriores ao próprio acontecimento, contêm duas histórias: a do crime ou da tragédia e a de seus antecedentes que englobam outras notícias semelhantes.

O jornalista-narrador conta não apenas "o que se passou efetivamente" ou explica de que forma tomou conhecimento daqueles fatos, como também transporta para o relato algo que já é, de alguma forma, de conhecimento do público. $\mathrm{O}$ texto apela a valores duais e deixa uma espécie de ensinamento moral em suspenso. Outra característica é a ênfase aos detalhes, os pormenores que enriquecem a narrativa. Ao particularizá-los, o narrador constrói uma sequencia textual na qual o leitor pode se visualizar. Lugares conhecidos, relatos comoventes de fatos que adquirem a marca da excepcionalidade. Pessoas comuns vítimas da violência, a mesma violência que faz parte da vida de muitos dos leitores. O sensacionalismo, ou as notícias de sensações, explora o desejo do extraordinário, do violento, do grotesco, do excepcional, que existe não apenas nos grupos populares, mas atravessa os grupos sociais.

Falar das transformações do jornalismo no final do século XIX e na primeira década do século XX é se referir a territórios midiáticos singulares que conformam processos semelhantes. Mas claro que essas transformações não foram unívocas. Em muitos lugares, continuou-se a praticar um jornalismo que mais tinha a ver com as práticas do século XIX: jornal de um homem só, aparecido ao sabor de interesses momentâneos, de poucas páginas, repleto de opiniões particulares e particularistas. 
Por uma história cultural latino americana dos meios de comunicação:...

$\mathrm{Na}$ história que estamos propondo resta ainda uma última referência para completar o circuito da comunicação: o público. Podemos desvendá-lo de múltiplas formas: pelos indícios que deixaram impressos nos próprios periódicos, pela literatura de época que fixa a forma como esses leitores retiravam sentidos das páginas que liam ou folheavam, pelos próprios textos publicados nos periódicos, já que ele, público, insere sua marca na leitura possível que realizou.

Esse é o exercício metodológico que deixamos para o final deste texto.

\section{Leituras e apreensões de sentido}

Partimos do pressuposto de que é possível recuperar o leitor do passado e, sobretudo, as interpretações que produziu com suas leituras múltiplas e plurais a partir das marcas que ele deixou inseridas na trama narrativa. No texto há uma pluralidade de significações construída na rede espacial e temporal, fazendo com que cada texto pertença ao escritor e ao leitor de ontem e de hoje. A escrita liberta o texto do autor, recolocando-o no lugar de sua significação.

Assim, os periódicos são pródigos em deixar registradas as marcas de leitura mesmo de leitores inomináveis. Mesmo aqueles que eles jamais admitiram como seus leitores, aparecem vez por outra contidos na trama. E a trama pode ser um velho anúncio de jornal ou uma notícia que revela as materialidades da leitura:

Era costume do carregador Domingos Paranhos Lorenzo, espanhol de 28 anos, solteiro [...], ir ler o jornal, montado no tablado, enquanto os operários trabalhavam lá em cima. Cerca de 11 horas da manhã, tendo-se ele munido do seu jornal foi para o local predileto saborear as sensações do noticiário. $\mathrm{O}$ homem mal sabia que estava fazendo a sua última leitura. De fato, quanto mais absorto ele estava na leitura, desprendeu-se do andaime uma grossa e pesadíssima tábua que veio de revés bater-lhe violentamente na nuca, jogando-o no chão, para a frente, com o crânio fendido, morto instantaneamente. (Gazeta de Notícias, 5 jan. 1907, p. 3) 


\section{Marialva Carlos Barbosa}

A notícia, publicada num jornal de grande circulação do Rio de Janeiro, dá informações preciosas não apenas sobre o leitor, o espanhol Domingos, mas sobre a sua leitura. O lugar onde a realizava: no trabalho, na hora do almoço, usando a pausa preciosa do dia. Domingos lia, sentado num tablado, mas a leitura levava-o a dar asas a imaginação, deixando-o absorto, envolvido com as "sensações do noticiário". Recriando o texto, distanciava-se da realidade. Como estaria Domingos entendendo os sinais daquelas páginas?

Começava ela a ler o popular órgão carioca pelas notas sociais. A seção de mundanismo, naquele tempo, abrangia do aniversário ao obituário, informando tudo sobre nascimentos, casamentos, festas, bailes, recepções, falecimentos e missas. Minha mãe explicava o seu interesse pela vida social como um dos meios pelos quais volta e meia tinha notícias de amigas de sua geração que se dispersavam depois que contraíram casamentos. (NETTO, 1977, p. 51)

A leitora, pelos periódicos, podia se inserir num mundo distante, recuperando um tempo passado que se tornava presente pela identificação de personagens conhecidos nas indicações esparsas fornecidas pelos jornais.

Vez por outra aparece uma indicação das emoções que a leitura trazia.

Lembro-me de que mamãe se queixava de que a heroína do folhetim não tinha sorte, quando as coisas da sua vida iam se arrumando e a felicidade começava a sorrir, lá vinha outra desgraça $[. .$.$] e era um desespero, tudo desandava. Coi-$ tada - dizia mamãe -, e eu procurava consolá-la dizendo que se Ana Maria ficasse feliz o folhetim acabava (Rubem Braga: In Jornal do Commercio, 1977, p. 8).

Recriando a emoção, apropriando-se do texto a partir da sua individualidade, vivendo como se fosse a personagem, sofrendo por ela e torcendo para a solução de seus problemas, a leitora identificava-se com a história, transportando-se para ela e tentando 
Por uma história cultural latino americana dos meios de comunicação:...

recriá-la. A sua vida comum tornava-se, a partir de sua inclusão naquele ambiente de sonho, romanceada. Vendo-se como a heroína do romance imaginado, sentia pena de seus sofrimentos, alegravase com seus sucessos, emocionava-se com os seus amores.

A leitura emocionada era feita de outra forma. Sussurrada com as amigas, comentada, ainda que rapidamente com o filho, que vendo o texto de outra maneira, o retira do universo de sonho. M Para o menino, Ana Maria era personagem. Para a leitora, Ana Maria era, como ela, mulher.

Essa pequena análise do universo do público a partir das marcas que eles próprios deixaram impressos nos periódicos é apenas um exercício interpretativo de uma história que, se propondo a remontar o circuito da comunicação e reconstruir os sistemas culturais do passado, não poderia deixar de incluir não apenas o público como uma presunção, mas os atos interpretativos que realizavam como leitores. A história que propomos inclui sempre no que denominamos territórios midiáticos as apreensões de sentido plurais que os leitores realizavam.

FOR A CULTURAL HISTORY OF LATIN AMERICAN MEDIA: A LOOK AT THE PRACTICES, PROCESSES AND COMMUNICATION SYSTEMS IN THE LAST DECADES OF THE NINETEENTH CENTURY

Abstract: The article discusses the theoretical and methodological perspectives that must be taken to think of a cultural history of Latin American media. It analyzes the theoretical difficulties of thinking about the media from the perspective of cultural history beyond specific cultural boundaries and spaces. Secondly, as a possibility presents analytical look at the prospect of a spatial area, such as media area, thinking practices, processes and communication systems to make possible the analysis from a historical perspective and cultural communication processes exist in several Latin American territories Americans. The points of the exercise are reflective transformations of the press in the last decades of the nineteenth century

Keywords: Communication. History. Methodology. America Latina. 


\section{Marialva Carlos Barbosa}

\section{Notas}

${ }^{1}$ Esse texto, com algumas modificações, reproduz a palestra, não publicada, e realizada no Seminário Internacional Historia de los Medios en America Latina, realizado na Biblioteca Nacional de Buenos Aires e promovido pela Universidade de Buenos Aires e pela Red de Historia de los Medios, em 2011.

\section{Referências}

BARBOSA, Marialva (2007). História cultural da imprensa. Brasil. 1900-2000. Rio de Janeiro: MAUADX. MAUADX.

(2010). História cultural da imprensa. Brasil. 1800-1900. Rio de Janeiro:

GINZBURG, Carlo (2007). O fio e os rastros. São Paulo: Companhia das Letras.

HELLER, Agnes (1993). Uma teoria da história. Rio de Janeiro: Civilização Brasileira MARTIN-BARBERO, Jesús (1987). Dos meios às mediações. Rio de Janeiro: UFRJ, 1998.

NETTO, Manoel Cardoso de Carvalho. Norte oito quatro. Rio de Janeiro: Editora do Autor, p. 51, 1977.

REVEL, Jacques (2009). Proposições: Ensaios de história e historiografia. Rio de Janeiro: EDUERJ.

RICOUER, Paul (2007). A memória, a bistória e o esquecimento. Campinas: UNICAMP.

Recebido em 13/06/2012

Aprovado em: 11/07/2012 